\title{
Nigeria and the Sustainable Development Goals: Why the Indigenous Languages Count
}

\author{
Ugwu, Eucharia Okwudili (M. Ed) \\ Ogunremi, Patience Opeyemi (M. Ed) \\ Department of Arts and Social Sciences Education, \\ University of Ibadan, Nigeria
}

\begin{abstract}
Language as a tool for logical thinking and planning is unavoidable in every developmental effort. Nigeria is among the countries that were not able to achieve the Millennium Development Goals (MDGs). Among the reasons given for Nigeria's low performance level was communication barrier. To achieve the Sustainable Development Goals (SDGs), the government has planned a transition strategy and hopes that it would be people-centred. Hence, she hopes to leave no Nigerian behind. As a multilingual nation, many Nigerians cannot function in English language but rely only on their various indigenous languages. Accommodating them in the SDG plans would require communicating with them in the languages that they understand. This could enhance collaboration and minimise a repeat of the previous failure. Unfortunately, there is no language plan in the government's transition strategy. If development is about helping people to help themselves, then there must be collaboration among the planners of the SDGs and those for whom it is planned. But collaboration is only possible where there is a free flow of information. This paper is an attempt to reposition the indigenous languages at the hearts of all effort to achieve the 2030 agenda in Nigeria.
\end{abstract}

Keywords: Sustainable Development, Nigerian Languages, Collaboration

\section{Introduction:}

Language use is an important attribute of human beings. Human beings rely on language for virtually everything they do. It guides and enhances critical thinking, making of informed decisions, expanding knowledge, sharing or transferring of such knowledge with and to one another as well as planning and executing of different projects in order to make life better. Language is also essential for cordial living which is facilitated by the establishment of laws and principles that guides everyday life. All these, and 
many more are made possible through the power of the word - written or spoken, which are the manifestations of language.

As thinking beings who are at the same time confronted every now and then with the problems and challenges of life, human beings have often resorted to finding ways to address life's issues. Human nature naturally abhors suffering, even though it is almost inevitable in the world. While some causes of sufferings like diseases and illnesses come naturally, many others are the results of human activities and inactivities. It is in an effort to control these forces of nature and curb the tendency of human beings constituting nuisance to one another and to nature itself that lie the whole idea of sustainable development.

The Sustainable Development Goals (SDG) is a target as well as yardstick for every country to measure and explore its response to and business of making life conducive for her present and future citizens. It is about recreating a safe world for all through equipping of every human being with the tools for a decent and healthy living through mutual effort. Language is needed to communicate the SDGs to all human beings and also to empower them to make meaningful contributions towards achieving those giant goals which will in turn make the world conducive for the present and future generations while protecting the other living and non-living things are all part of creation.

Development entails the full realization of the human potential and a maximum use of the nation's resources for the benefit of all (Bamgbose, 2011). If development is about human beings, then that which gives human beings the capacity to function cannot but be so important. Thus, British Council (2017) explained that since development is about sharing experiences and ideas to find better ways of working together as human beings, the languages of initiative, of education, of trade, of creative expression, of justice and of peace-building, are so crucial to sustainable development.

Nigeria is home to over 500 languages spoken by her numerous ethnic groups. Developing these indigenous languages will aid in bringing the sustainable development initiatives to the grassroots where they are actually needed. This is because, communicating those initiatives to the people, and getting them to understand, accept, and collaborate in achieving them will not only be enhanced but be made possible if the goals are explained in a language people understand clearly. Meaningful development is not possible in Nigeria as long as the indigenous languages are left behind. Using the indigenous languages will enable the citizens to express their needs, understand the plans of the government, and collaborate to make those plans possible and fruitful (Ugwu 2017, 120). If development includes collaboration for the common good, then language matters. 


\section{- Multilingual education in Nigeria and the SDGs Agenda}

That language plays a leading role in education is not questionable. Education on the other hand opens the door to development. The Organisation for Economic Co-operation and Development (OECD) (2017) recognised education as 'the foundation for promoting development, reducing economic disparities and creating a society of inclusiveness'. Nigeria is an exceptionally multilingual nation. In theory, she practices a multilingual system of education which implies that more than two languages are used in school. The mother tongue-based multilingual education system theoretically operates from preprimary to primary three while English is the language of instruction from primary four upward. In practice however, English language is the preferred medium of instruction and is therefore used at all levels in most schools.

There are several arguments and reasons as to why Nigerians prefer English medium- of-instruction, even against the directives of the country's language policy. Although such details are outside the scope of this work, one of the reasons is that English is seen as the language of the elites, and therefore, proficiency in it is considered the road to upward mobility. The preference for English is highly promoted by the private schools, who, as collaborator in education, have often capitalised on the use of English at all levels since this has become one of their easiest marketing strategy. It is assumed that speaking 'good English' is equivalent to quality education, and invariably, better prospects in life. This is irrespective of the fact many students also come out from these private schools and are still not able to function as expected.

Meanwhile, the inefficiencies in the government schools have led to the proliferation of private schools at all levels. Even though these schools are of high standard with better infrastructures - compared to the public schools and have uninterrupted academic sessions, the high fees they charge often make them inaccessible to the majority poor (Ugwu 2017, 125). Besides, preprimary education is currently in the hands of the private sector and as the saying goes, he who pays the piper dictates the tone. These children are taught all the school subjects in English language starting from their first day in school (despite the fact that the National Policy on Education (NPE) stated that the indigenous language should be used at this level). Since the government has failed to deliver quality education, the private school administrators and elite parents are now the key players. They have literarily hijacked the language policy and turned both the weaknesses in it and the indifference of the government to their own economic advantage, while the makers and owners of the NPE are standing aside as stunned audience. How can the policy work when the policy makers seems less concerned and 'powerless'? This trend has continued to perpetuate inequality by widening the gap between the rich and the poor and is therefore a major hindrance to the achievement of the SDGs, especially equitable and quality education which is 
needed to facilitate the achievement of the other goals. Illiteracy has been acknowledge as 'an obstacle to the economic, cultural and social development of African countries and mass literacy campaigns cannot succeed without the use of indigenous African languages' (Chimhundu, 1997:51).

Theoretically too, the Nigerian school system is supposed to ensure inclusiveness in education through training of specialist teachers in different subjects, including Sign Language. Furthermore, the Universal Basic Education (UBE) was instituted to reduce incidence of drop-out from formal school system, through improved relevance, quality and efficiency (NPE 2014). Going by the first statement, every Nigerian public school should have Special Education teachers. In spite of these statements in the NPE, the present situation is that the world's most linguistically diverse countries (of which Nigeria is among), many of which use a single national or international language for schooling, account for 58\% of primary school-aged children out of which 54 million are out-of-school, that is, $72 \%$ of the out-of-school children worldwide (Pinnock and Vijayakumar, 2009). To be more specific, the Education for All (EFA) Global Monitoring Report (2013, 11-13) shows that at 2008 many Nigerian children drop out of school due to poverty, that almost three-quarters of the poorest in 7-16 year-olds in the northeast had never been to school, and that 9 out of every 10 young women did not have the chance to complete primary school. Also, in the southeast, $24 \%$ of the poorest were without primary education, compared with $2 \%$ of the rich. The Nigerian government is yet to make serious commitment to address most of the major issues that contribute to keeping children out of school, including poverty, language, disability and gender. With each passing year, the situation is getting worse. By year 2016, the Global Education Monitoring Report shows that by 2010, 8.7 million Nigerian children of primary school age were out of school; the 'percentage of the poorest females who had never attended school increased from $46 \%$ in 1999 to $76 \%$ in 2013' (Global Education Monitoring Report, 2016, 16).

Almost in every part of the world, the mother tongue has been identified as the best language through which children can learn. Therefore, for a country like Nigeria with numerous languages, the use of English alone for education has done and will continue to do more harm than good to students and the society. Apart from the pedagogical advantage, mother tongue bilingual education (MTBLE) makes the child's language, culture and context the foundation of learning and gives a sense of inclusion to the natives who speak the language (UNDP, 2016) and (Pinnock and Vijayakumar, 2009). If the goals of education as stated in the NPE are to be achieved, there is no alternative to making education bilingual or multilingual by using English and the indigenous languages. UNESCO Bangkok (2012) noted that school systems that do not use learners' own languages or respect their cultures make 
it extremely difficult for children to stay in school and learn. This, according to the document has threefold implications: it perpetuates cycles of marginalization and discrimination by excluding a large portion of the population from good quality education, delays economic growth and perpetuate conflict and political instability. Using a language other than the children speak at home to teach them has been linked with drop out, low achievement and low self-esteem (Global Education Monitoring Report 2016b). At the long run, the individuals, communities and the countries are affected. Romaine (2013) had predicted that the neglect of language, more specifically 'failure to support multilingual education policy will hamper the achievement of the Millennium Development Goals (MDGs)' because 'the poorest groups in society tend to have least access to the dominant languages favoured at school'. Nigeria is among the countries that failed to achieve the MDGs.

That the standard of education in Nigeria has fallen almost beyond repair is not far from the truth. The school curriculum is often at odds with what the job market requires. The Nigerian school system is certificateoriented and this has often led to massive examination malpractices. Many school leavers especially after secondary education are not able to defend their certificates. There has been a sort of power tussle between the education sector and the government on the criterion for admitting candidates into the university. Candidates who are admitted into the university on the basis of their performances in West African Senior Secondary Certificate Examination (WASSCE) and the Unified Tertiary Matriculation Examination (UTME) are sometimes not able to cope with the academic demands of university, as a result of which universities often resort to conducting other forms of assessment before the admission. However, Ugwu (2017, 135) links the recurring problems in the Nigerian education, including incessant examination malpractices to the society's ignorance of a connection between the 'process' and 'product' of education. According to the author, the educational system is certificate-oriented as against practical and actual knowledge; hence, students are not academically equipped to face the challenges of life, including examinations. Underneath the problem is the inability of students to articulate their thought in English language. All these retard growth and jeopardises the future of the young people whole ought to be the champions of sustainable development. A multilingual system of education would reduce the present over-dependence on English language which is a major barrier to both inclusion and quality education in Nigeria.

The term 'inclusion' as it pertains to SDG has many implications, among which are accommodating people with disability and the linguistic ethnic minority in the plans. It is true that some special schools exist in Nigeria, the world has moved from isolating the physically challenged by 
keeping them in these special schools. While the Nigerian government has paid attention to nomadic education, there seems to be no plan for children with disability (especially the hearing and visually-impaired) in the country. No subject like Sign Language and Braille are in the NPE and the promise to train 'more special teachers' is yet to be accomplished. A physicallychallenged ought to be able to make a choice as to which school to attend based on factors such as proximity, quality and cost. This would mean ensuring that most public schools have provision for these groups of people by providing them not only with the needed special teachers and materials but also making the environment disability-friendly. Unfortunately, this is far from the reality in Nigeria. Only few Nigerian universities have Special Education Departments and the existing ones are far from providing disabilityfriendly environments for these groups of people. This make the special-needs students go through a lot of hazards in order to receive education. Yet, for persons with disabilities, inclusion and accommodation are critical to empowering them to live independently, find employment and contribute to society (UNDP, 2016).

Another group of people that are highly neglected in Nigeria are the linguistically minority groups. This is largely due to the neglect of their languages in education and the public domain, including in politics. Many Nigerian universities are yet to establish indigenous languages departments. This means that the development of the languages, including preparing the teachers that could teach in and with them is yet to be included in the Nigerian government's agenda. A study by Ugwu (2017, 115-116) shows that among all the indigenous languages in Nigeria, only Yoruba and Igbo are offered by the University of Ibadan and even these two are hardly patronised by students. The study further revealed that 'from 2014 to 2016, over $40 \%$ of the languagebased B. A. students offered English; slightly below this was modern European languages (about 36\%)'. This was followed by Arabic (10\%) and those that studied the indigenous languages continue to rank low with just about $7 \%$. This means that most students preferred studying the imported languages such English, French and German to the indigenous ones. Although the population of the study is too small to generalise, this may not be different from what is obtainable in other Nigerian universities. Many studies have shown the preference for English language to the indigenous languages among different segments of Nigerian both for education and other functional domains. If this trend continues, then the mother tongue-based bilingual education may still not in sight in Nigeria.

Pinnock and Vijayakumar (2009) explain that for children at the preschool and primary level, teaching them in an unfamiliar language is often too demanding for them, and this problem is compounded when they face other barriers to education like poverty, hunger and poor learning condition. 
The Nigerian child has all these factors to contend with! Bamgbose (2011) adds that the argument that exposing children to the imported official language as soon as possible to enable them learn it better neglects the fact that learning through a language in which one is not competent may as well produce poor results. Indeed, the poor result is very glaring in the entire system of Nigerian education and this goes for all levels. The poor and their children are the most affected and some are gradually giving up their languages therefore limiting their ability to think creatively and contribute to sustainable development.

With an existing language policy that is not being implemented, the implication is that language will remain a big problem in Nigeria's actualisation of the sustainable development goals. The use of English language in education has been associated with the inability to cope with the language of instruction and eventual dropping out of many students. Also, without the use of the indigenous languages in education, adult literacy programme will continue to be hampered since most adults are not proficient in the English language, which is mainly learnt in school. There can be no true development without linguistic development, noted Romaine (2013) and the only way forward is for the Nigerian government to take an urgent action by developing the indigenous languages.

The Organization for Economic Cooperation and Development (2017) explains that education is a foundation block for nearly every other SDG: it saves lives, improves health, and fosters shared understanding and values. Education matters because it is extraordinarily difficult for persons without good education to have a secure economic livelihood, peace of mind, selfsufficiency, and self-respect (Kpolovie, (2017). However, the quality of education matters as much as education itself. Apart from the disparity based on gender, etc., the poor make up about $90 \%$ of those in the Nigerian public schools where activities are often marred by frequent industrial strikes, poor infrastructure, and lackadaisical teachers, among others. The poor infrastructure and irregularities in the school system is enough to discourage children from going to school or to come out without being able to read or write. The Global Education Monitoring Report (2016, 20,28) shows that as at 2013, over $90 \%$ of children of rich parents in Nigeria, irrespective of whether they are from rural or urban areas were likely to complete lower secondary education but among the poor, just about 3\% of females and 17\% of males completed lower secondary school. In the North West zone, only $4 \%$ of poor young women can read, compared with $99 \%$ of rich young women in the South East. Even though the males have a slight advantage over the females in terms of education, this statistics still presents a gloomy picture for the poor ones, irrespective of gender. Without education, it is impossible for these poor people to maximize their potentials and to even get decent employment. 
If education matters in development, so does language; if collaboration matters too, so does language all the more because sustainable development is also about maximizing production of goods and services through collaborative effort. And production is cooperation, is communication, and is language (Wa Thiong'o 1986). But it is not just any language but the one that is mutually intelligible. Without language, communication is not possible and when there is a communication barrier, collaboration which leads to the achievement of the common goals becomes impossible. The message of Dr. I. M. C. Chombo, chairman of the National Commission for UNESCO at the Intergovernmental Conference of Language Policies in Africa is all the more relevant in Nigeria today. According to him, a language that people expresses themselves fully in is the one through which they can think and dream. Hence, it is 'too much to demand originality and creativity from a person who is a toddler in a particular language', which is what happens 'when in an attempt to galvanise our nationals into activity, we drum messages into their ears in tones that are incomprehensible to them' (Chimhundu 1997, 79).

Language is important for communication, participatory democracy, access to justice and information on health; thus, without language that makes these possible, a citizen is virtually excluded from national life (Bamgbose, 2011). Article 13 of the African Charter states that 'every citizen shall have the right to participate freely in the government of his country, either directly or through freely chosen representatives in accordance with the provisions of the law' (African Charter, 1986). This participation includes access to relevant information from and about the government and governance. These are made possible through appropriate use of language. If the citizens have no access to such information or if the information is truncated on the basis of their language, the citizens' basic right is denied them or violated.

Nigeria is estimated to have lost over $\$ 400$ billion to corruption between independence and 1999 (UNDP, 2016). The rural people lack the power to demand accountability from the leaders and fight corruption because they have no voice (they are toddlers in the English language). Their language is not recognized. By forcing them to learn English language, the power of divide and rule, once used by the colonial masters is planted and their chord of unity is broken. Sallabank (2010) adds that people who are not fluent in their country's national or official languages may be denied access to education and media, and that inadequate translation may as well deny them access to justice. It also hinders genuine participatory democracy which relies on two-way communication, slows down national integration, creates insecurity and feeling of inferiority (Lodhi, 1993) and UNESCO Bangkok, 2012). Chimhundu $(1997,63)$ makes a strong case for multilingual education in Africa, to ensure participatory democracy: 
Democratising language policy... is a matter of responding to the real needs of the people. ...this would mean promoting multilingualism in many African countries. For instance, how can you guarantee democracy when the law of the land is not understood in the language of the people? How do you abide by what you do not know? How can you use information to which you have no access or to which you only have limited access? How can you fully participate in anything, or compete, or learn effectively or be creative in a language in which you are not fully proficient or literate? Above all, how can a country develop its human resources base to full potential without the language of the people?

Since Nigeria has about 519 languages (Simons and Fennig, 2018), it is high time the government started developing them gradually to make them functional in the school system and beyond. Although in most African countries, the official imported language is spoken by just about $10-20 \%$ of the population (Bamgbose, 2011) and (Chimhundu, 1997), it is assumed that just about $20 \%$ of Nigerians can function in English language - yet, it is the language of education, governance, law, commerce and including, of course, development! If English is the only language that the government speaks, and she is the champion of sustainable development, then it is also the language of development. Now is the time to act, and the indigenous languages must be the language of action.

\section{- From the MDGs to the SDGs: Learning from the past}

To understand or make sense of our present and plan for the future, it is very important not to ignore the past. To take the past for granted is to jeopardise the future. The year 2015 saw the folding up of the MDG and the unfolding of the SDGs. But prior to the expiration of the MDG target, the Statistics Division, Department of Economic and Social Affairs of the United Nations released a progress chart showing how different countries had fared in ending extreme poverty and hunger, improving education, gender equality, child survival, health, environmental sustainability and global partnerships which were the millennium development goals. The report shows a low performance by sub-Saharan African countries which Nigeria happen to one of them. The summary was that the region scored low in almost all the positive attributes but high in negative attributes such as hunger, poverty, unemployment and diseases. Although there was moderate enrolment in universal primary education, the rate of maternal mortality remains high while access to reproductive health was low. The proportion of the population with improved drinking water and sanitation was very low while there was very high proportion of slum-dwellers. The last goal which was to develop a global 
partnership for development shows that there was very low proportion of internet users. Even though Nigeria claims to made substantial progress especially in the health sector, there are still more to be done as shown in this report.

\section{Overview of Nigeria's Transition Agenda:}

Bearing in mind the successes and failures recorded during the MDG period as well as the new challenges confronting the country, the Federal Government came up with an agenda for smooth transition from the MDG to the SDG. The document was release on October 2015. It asserted that the country 'registered mixed results across the goals, geographic areas and gender groups' and that 'despite progress on some indicators, many of the goals and targets have not been met' - an honest assessment indeed (The Presidency, MDGs Nigeria, 2015). On the health sector, the success story, according to the document included, nearness to polio eradication, implementation of a Conditional Grants Scheme (CGS) and mobilizing community utilisation of health facilities through the village health workers scheme.

On the failure side, it reported that the stakeholder advocacy, from the state to the local community level was very weak due to lack of materials produced in local languages that would have increased awareness and strengthened implementation, etc. It was also noted the external consultants who carried out a number of critical activities did not succeed in knowledge transfer. One can infer from the situation that the knowledge transfer failed because of language barrier between these 'experts' and the local people. With the above in mind, Nigeria's vision for the SDG was to:

i. Leave "no Nigerian" Behind (emphasis ours)

ii. Integrate the SDGs in an "inclusive and people-centred" manner (emphasis ours) and

iii. Focus on institutional and policy strengthening through four objectives: New Institutional Mechanisms, Policies, Domestication/Localisation and Financing/Investments (p.5)

To make the actions more concrete, the four objectives were further broken down into seven frameworks among which are Institutional, Policy and Legal, Human Resources, Communications and Financing Frameworks.

Since the concern of this writing is on language, we shall examine the place of language in this strategic plan. But it might be interesting to note that in the entire document, language was mentioned just three times, yet, communication was identified as one of the major obstacles to the realisation of the MDGs. Moreover, one of the new plans is to employ 'innovative techniques to improve understanding of the SDGs, communicating effectively across all levels of government, and permeating across all echelons of society, 
with a focus on inspiring every community to innovate, motivating Nigerians to implement the goals' (p.28). Since the Press/Communications unit was supposed to play a leading role in the mission, the communication plan (not language plan) was to ensure 'that the offices are properly equipped with materials and personnel, who must be 'seasoned individuals with the necessary technical skills to formulate communication and stakeholder engagement strategies, develop the right communication materials and messages to reach the right audiences, as well as maintain the website and engage in social media'.

As far as this document is concerned, there is no plan to bridge the communication gap between the planners and those for whom the plans were made. In other words, there is no concrete language plan! In which language or languages are these 'seasoned personnel' supposed to communicate Nigerians, bearing in mind that they are not to leave any Nigerian behind? Since the language of governance is English, lack of language plan means that English would invariably be the choice. If only about $10-20 \%$ of the population can function in the governments' language (English), how does this giant SDG plans concern millions of the citizenry? Indeed, this transition plan has already been planned to fail, unless it is the business of the Nigerian elites alone. And if this plan is meant for all Nigerians, then it must be a gross injustice to leave a great number of citizens in the dark. The failure of many development programmes in Africa has been linked to communication breakdown arising mostly because the indigenous languages which the people understand were not used for drawing up such plans (Chimhundu, 1997) and (Iwara, 2008). Also, Bamgbose (2011) stated that only a small part of the populace can be involved in a development strategy based on the use of an imported official language (Bamgbose, 2011). Studies have confirmed that implementation of sustainable socio-economic development projects are more successful if the local languages are used and the target population are allowed to participate (Nwobia and Noah 2014).

However, even though language is an important tool needed for the achievement of the SDGs, it is not given any significant attention in Nigeria's Transition Agenda. In the three places where language is mentioned in the document, the first was to identify it as a major hindrance to the actualisation of the SDG. In the second and third places, it was downgraded with a conditional phrase, thus presenting it as optional:

i. Limitations included the lack of materials produced in local languages that would have increased awareness and strengthened implementation (p.29)

ii. ...some of the toolkits can be adapted to serve the Nigerian context and produced in local languages where applicable (p.30 emphasis ours). 
iii. $\quad$ Where appropriate, the use of mass text messaging, at the community level and in local languages will be deployed to disseminate information (p.29, emphasis ours).

UNESCO Bangkok $(2012$, p.) observed that "by failing to explicitly articulate language in key international and national poverty reduction documents, or in communications planning, the unique situations of ethnolinguistic minorities and the particular problems they face in being included in development processes is equally ignored". This is exactly what Nigeria has done.

\section{- Looking beyond Nigeria's Agenda and Vision for the SDGs}

Three years into Nigeria's plan for action, the country is yet to reach any significant milestone in terms of achieving any of the SDGs. On the contrary, there is increased hunger, diseases and famine. The looming crisis in different parts of the country is pushing her to the verge of disintegration. Displacement of citizens through the incessant attacks of Boko Haram and armed Fulani herdsmen happen almost on daily basis. The establishment of Internally Displaced Persons' camps (IDPs) has become a norm, rather than an exception in Nigeria. These displaced persons who were previously subsistent and commercial farmers now rely on humanitarian aids to survive while their once fertile agricultural lands have been left desolate or used for cattle breeding. This means, the displaced are not only unable to contribute to national development but have been made 'burdens' to the already scarce resources. Most of the displaced persons are women and children, which makes them even more vulnerable to poverty, disease and hunger. They have neither access to justice nor to education.

Migratory tendency has increased among the uncountable hopeless youths. Nigerians are found in almost every corner of the world as migrants in search of greener pastures. Some pass through unimaginable circumstances and disappointment. Many die on the road and sea while some others are either deported or are held as slaves. Also, rising crisis means food shortage, insecurity, hunger, lack of access to education, health care and sanitation, loss of linguistic and cultural diversity which can lead to a feeling of hopelessness and despair as well as increase in social, religious and political intolerance, among others. All these are contrary to the goals of sustainable development. Thus, rather than closing the inequality gap in Nigeria, it is being widened.

The above challenges present an incredibly gloomy picture of Nigeria but unfortunately, it is the present reality. There are yet other more depressing issues facing Nigeria. For example, on the global scene, statistics shows that women are discriminated against with respect to opportunities in many parts of the world (UNDP 2016). However, while gender bias is a global issue, Nigeria, being one of the countries in the sub-Saharan Africa is worse hit by 
this reality. A woman dies from complications in childbirth every minute majority of them in developing countries and a woman in sub-Saharan Africa has a 1 in 6 chance of dying in pregnancy or childbirth, compared to 1 in 4,000 in a developing country (UNICEF, /HQ04-1219/Vitale). The UNICEF (2015) report is even more specific: in Nigeria, 53 out of every 1,000 live births die within 4 weeks; one million children die each year before their $5^{\text {th }}$ birthday (195 out of every 1,000 live births), and $58 \%$ of the deaths is due to malnutrition. Life expectancy at birth is 48years while infant mortality is 100 per 1000 live births. Also, 14\% of Nigeria infants are underweight at birth and antenatal covers only $58 \%$ of the women. For every 100,000 live births, 800 women die through childbirth. Girls are not left out of the scene: from 1987 to 2005 , child marriage was 43\%. More so, an estimated 44,800 Nigerian women die from pregnancy related complications out of 5,600,000 pregnancies.

In terms of educational opportunities, the EFA Global Monitoring Report $(2013,2)$ shows that in Nigeria, $70 \%$ of the poorest females (aged 7 16) have never been to school, and $84 \%$ of the poorest young women (aged 15-24) have not completed primary education. In terms of Human Development Index (HDI), Nigeria is among the countries with low HDI. Her HDI value was 0.527 , and her rank was 152 out of 188 countries and territories. The report also showed a wide gap between males and females in Nigeria: the female HDI value was 0.482 as against 0.569 for males (UNDP, 2016 , p.). These reports are clear indications that the vulnerability of Nigerian women has many faces: educationally, socially, financially and even politically. This impacts on their quality of life, reduces their chances of living a healthy and fulfilled lives and deprives them of contributing to the development of the country.

The Nigerian government therefore, needs to empower women through adult literacy programmes and lifelong learning (SDG 4) to enable them live life to the fullest. If adult literacy is to be efficient, the indigenous languages remain the best medium that could be used because it will be impossible for these women to receive instruction in a language they are not proficient in. An educated and empowered woman is able to make decisions that can positively contribute to her own wellbeing, those of her children, and the society at large. This includes nutritional, health, education and financial decisions. Doing otherwise will continue to widen the gap between the haves and the have-nots in the society and clog the wheel of sustainable development.

The saying that if you educate a single woman, you educate the human race holds true for Nigerian women. Women make the most important decision about their children such as sanitation, health, nutrition and basic day to day living activities. All these contribute to the wellbeing of the children, their healthy status and how the children will grow to see themselves. The 
rural women rely on their indigenous languages for this information, to circulate it among themselves and utilise them appropriately without misinterpretation. Health information is better transferred to the rural women in a language that is familiar to them and in ways that engage with their cultural context (UNESCO Bangkok, 2012).

The rural farmers equally need to understand current innovations in agriculture, pest control, the harmful effect of some chemical, and how to boost farm yields with less stress. In an era where industrial pollution is on the increase, use of plastic bags are contributing to loss of biodiversity, and rampart cutting down of trees are increasing desertification, the rural people also need to be educated to enable them see the connection between their daily activities which are sometimes taken for granted and the menace of global warming. To achieve this, they must be spoken to in a language that they understand fully. The message of Gro Harlem Brundtland that 'Unless we are able to translate our words into a language that can reach the minds and hearts of people young and old, we shall not be able to undertake the extensive social changes needed to correct the course of development' (World Commission on Environment and Development 1987, 8) is a necessary reminder of the importance of language to the achievement of the SDGs.

\section{- Suggestions and Conclusion}

Language remains a useful tool for the actualisation of sustainable development in every society. But in a multilingual country like Nigeria, there is no alternative to the use of the indigenous languages through which people can function. Using the indigenous languages in developmental effort will reduce the chances of communication barrier which was a major hindrance to previous developmental effort. However, a greater percentage of the said languages are not fully developed, and therefore, are not empowered for use in most public domains, especially in education and other key sectors. Therefore, there is a great and urgent need for the government to fulfil the consistent promise it has made in the NPE by developing the orthographies of many Nigerian languages.

Educators as nation-builders must also rise up to expectations by playing their own roles in promoting indigenous language education. It took a single language teacher, Lu Zhuangzhang, to initiate language reform for mass literacy in China (Wan, 2014). Building on that single initiative, China is now far ahead many countries in terms of development. Educators in Nigeria can do more. In their advocacy for better payment and infrastructures, they should also consider agitating for the promotion of the indigenous languages so that every Nigerian university can accommodate more of them. This will facilitate the training of more teachers that will teach the indigenous languages at the primary and secondary school levels, promote inclusion and create more 
employment opportunities for the youths. Teachers should also advocate for inclusiveness in the schools, starting from making the school environments disability-friendly. Failure to act might make educators lose their age-old identity as change agents.

If the 2030 Agenda is meant for every human being, and if indeed Nigeria's plan is to leave no Nigerian behind, in this agenda, then women inclusion can no longer be taken for granted. The extent of Nigerian women's vulnerability has been shown in the different reports mentioned above and the indigenous languages still hold the key to their emancipation from the shackles of poverty, disease, hunger, illiteracy and lack of opportunities. Recognition of and concerted effort to promote the indigenous languages will give hope their speakers, especially those who live at the margins of the society and feel abandoned by the government. This will promote political participation, peaceful coexistence and make the country's vision come true.

\section{References:}

1. African Charter on Human and Peoples Rights (1981). Retrieved from http://www.humanrights.se/wp-content/uploads/2012/01/African-

Charter-on-Human-and-Peoples-Rights.pdf

2. Bamgbose, A. 2011. African Languages Today: The Challenge of and Prospects for Empowerment under Globalization. Retrieved October 4, 2017 from http://.lingref.com/cpp/acal/40/paper2561.pdf

3. British Council (2017). Language and the Sustainable Development Goals. $12^{\text {th }}$ International language and development Conference, Dakar. Retrieved from https://www.britishcouncil.com.sn/en/programmes/language..

4. Chimhundu, H. (ed.) 1997. Language Policies in Africa: Intergovernmental Conference on Language Policies in Africa, Harare, Zimbabwe. Final Report (Revised). Harare: UNESCO. Retrieved August 6, from http://unesdoc.unesco.org/images/0014/001457/145746e.pdf

5. Emeka-Nwobia, N. U. (2015). The place of indigenous Nigerian languages in national development. Research on Humanities and Social Sciences, 5(12), 112-116. Retrieved from http://www.iiste.org/Journals/index.php/RHSS/article/download/2344 $\underline{8 / 2416333}$

6. Global Education Monitoring Report (2016). Gender Review. Creating sustainable future for all. Retrieved from http://gem-report2016.unesco.org/en/gender-review/

7. Global Education Monitoring Report (20166). Policy paper 24. Retrieved from http://unesdoc.unesco.org/images/0024/002437/243713E.pdf 
8. Iwara, A. U. 2008. The Linguistic Situation in Nigeria and its Implication for Sustainable Development. An Inaugural Lecture. Ibadan. Ibadan University Press.

9. Kpolovie, P. J., Ewansiha, S. and Esara, M. (2017). Continental Comparison of Human Development Index (HDI). International Journal of Humanities Social Sciences and Education (IJHSSE) Volume 4, Issue 1, PP 9-27 http://dx.doi.org/10.20431/23490381.0401002. Retrieved

from https://www.arcjournals.org/pdfs/ijhsse/v4-i1/2.pdf

10. Lodhi, A. Y. (1993). The Language Situation in Africa Today. Nordic Journal of African Studies 2(1): 79-86. Retrieved from http://www.njas.helsinki.fi/pdf-files/vol2num1/lodhi.pdf

11. OECD (Organization for Economic Cooperation and Development). (2017). Education at a Glance 2017: OECD Indicators, OECD Publishing, Paris. http://dx.doi.org/10.1787/eag-2017-en

12. Pinnock, H. and Vijayakumar, G. 2009. Language and education: the missing link. Retrieved on December 6, 2017 from http://www.unesco.org/education/EFAWG2009/LanguageEducation. pdf

13. Romaine. S. (2013). Keeping the promise of the millennium development goals: why language matters. Applied Linguistics Review, 4(1), 1-21. Retrieved from https://www.degruyter.com/view/j/alr.2013.4.issue-1/applirev-20130001/applirev-2013-0001.xmll

14. Sallabank, J. 2010. Language Endangerment: Problems and Solutions. eSharp, Special Issue: Communicating Change: Representing Self and Community in a Technological World, 50-87. Retrieved from http://www.gla.ac.uk/media/media_141050_en.pdf

15. Simons, G. F. and Fennig, C. D. (eds.). (2018). Ethnologue: Languages of the World, Twenty-first edition. Dallas, Texas: SIL International. Online version: http://www.ethnologue.com

16. Statistics Division, Department of Economic and Social Affairs, United Nations (2015).

17. Millennium Development Goals: 2015 Progress Chart. Retrieved from http://www.bing.com/fd/ls/GLinkPing.aspx?IG=FBC0E0C424874C5 083717153ED268736\&\&ID=SERP, 5116.1\&SUIH=jrUC-

WKJ85h78UnkHdgG8g\&redir=aHR0cDovL3d3dy51bi5vcmcvbWls bGVubml1bWdvYWxzLzIwMTVfTURHX1JlcG9ydC9wZGYvTUR HJTIwMjAxNSUyMFBDJTIwZmluYWwucGRm

18. The Federal Republic of Nigeria. 2014. National Policy on Education.

19. The Presidency, MDGs Nigeria (2015). Nigeria's Road to SDGs: Country Transition Strategy Retrieved from 
http://www.ng.undp.org/content/dam/nigeria/docs/IclusiveGrwth /Nigeria\%20transition\%20strategy\%20to\%20SDGs.pdf

20. Ugwu, E. O. (2017). Promoting Nigerian languages beyond the $21^{\text {st }}$ century: problems and Prospect. In D. O. Fakeye, S. A. O. Oladunjoye, I. A. Alade, B. O. Kayode- Olawoyin, O. R. Bateye, S. O., Olatunji, and O. S. Jayeoba (Eds.). Further thoughts on language, education, and the curriculum nexus for sustainable development in Nigeria. Ibadan: Constellation Books. 107-145.

21. UNDP (United Nations Development Programme). (2016), Human Development Report 2016. Human Development for Everyone. Retrieved from http://hdr.undp.org/sites/default/files/2016_human_development_rep ort.pdf

22. EFA Global Monitoring Report (2013). Inequalities in Education. Retrieved from Retrieved from http://unesdoc.unesco.org/images/0022/002204/220440E.pdf

23. UNESCO Bangkok (2012). Why language matters for the Millennium Development Goals. Retrieved from http://unesdoc.unesco.org/images/0021/002152/215296e.pdf

24. UNICEF, (2015). Achieving the MDGs in Nigeria. Downloaded from https://www.unicef.org/wcaro

25. UNICEF, /HQ04-1219/Vitale). Goal: Improve maternal health. Downloaded form https://www.unicef.org/mdg/maternal.html

26. World Commission on Environment and Development. (1987). Our Common Future. Chairman's forward. Retrieved from http://www.undocuments.net/our-common-future.pdf

27. Wan, D. (2014). The History of Language Planning and Reform in China: A Critical Perspective. Working Papers in Educational Linguistics 29(2): 65-79. Downloaded from http://www.gse.upenn.edu/wpel/sites/gse.upenn.edu.wpel/files/29.2W an.pdf

28. Wa Thiong'o, N. (1986) Decolonising the Mind. Retrieved from https://archive.org 